\title{
Analysis of Present and Future Financial Viability of High-Concentrating Photovoltaic Projects
}

\author{
Steve Tomosk, David Wright, Karin Hinzer and Joan E. Haysom
}

\begin{abstract}
Three metrics for the financial analysis of high-concentrating photovoltaic (HCPV) systems are assessed: capital costs for fully installed systems (in \$/W), the levelized cost of electricity [in \$/kilowatt-hours $(\mathrm{kWh})$ ], and the net present value [NPV (in \$)]. First, capital costs for HCPV systems are shown to have fallen at a steady rate and are characterised by a learning rate of $18 \%$ with a $90 \%$ confidence interval of 14-22\%. The analysis further combines this learning rate with future scenarios for volume growth rates to provide "lower," "middle," and "upper" projections for future capital costs of HCPV systems. These capital cost projections are used as inputs to the LCOE and NPV calculations, from which present and future project viability is assessed for a number of different project conditions. A case study for an HCPV deployment in Las Vegas exhibited an LCOE of \$0.125/kWh in 2014 under the "middle" capital cost scenario, which decreases to $\$ 0.072 / \mathrm{kWh}$ by 2020 . For project locations and situations where electricity rates vary according to different hours of the day, the NPV calculation provides a better assessment of financial viability. A detailed methodology with month-hour computation of revenues was developed and applied to two offsetting case studies: Las Vegas, Nevada (with time-of-use electricity prices for small businesses) and Ottawa, Ontario (with a large business rate structure that depends on peak demand). HCPV provides a good match for peak demand times, and the correspondingly high tariffs improve profitability compared with flat electricity rates. Both case studies exhibited profitability by 2015 (2018) under the "low" ("middle") capital cost scenarios. The research as a whole indicates that HCPV systems are already competitive with other solar energy technologies and in certain locations may already be able to deliver market-competitive
\end{abstract}

\footnotetext{
S. Tomosk - D. Wright

Telfer School of Management, University of Ottawa, 55 Laurier Ave. E, Ottawa K1N 6N5, Canada

K. Hinzer · J.E. Haysom $(\bowtie)$

SUNLAB Centre for Research in Photonics, University of Ottawa, 800 King Edward, Ottawa K1N 6N5, Canada

e-mail: jhaysom@uottawa.ca

(C) Springer International Publishing Switzerland 2015

P. Pérez-Higueras and E.F. Fernández (eds.), High Concentrator Photovoltaics,

Green Energy and Technology, DOI 10.1007/978-3-319-15039-0_14
} 
electricity costs. As prices continue to fall between now and 2020, many more projects will be profitable in both high- and low-DNI locations depending on the electricity rates and their structure.

\section{Introduction}

In this chapter, we describe some of the financial analysis necessary to show the economic viability of high-concentrating photovoltaic (HCPV) systems. We take the perspective of the HCPV system manufacturer as well as that of the owner/manager of an installed system, both of whom need to show a profit on their part of the supply chain for solar-generated electric power. We cover the current situation at the time of writing, i.e., the fourth quarter of 2014 , as well as projections over the remainder of this decade.

HCPV system manufacturers play into a quickly growing but highly competitive market for solar energy technologies, thus competing against established options such as silicon PV and concentrating solar power. An important metric on which they compete is the capital cost of a complete installed system, which is measured in dollars per watt $(\$ / W)$. Dollars is the price at which the complete systemincluding modules, racking, trackers, inverters, cabling, and installation - is sold to the solar farm (herein assumed to be 2014 US dollars). Watts is the peak direct current (DC) power generated by the system in Concentrator Standard Test Conditions of $1 \mathrm{~kW}$ of solar irradiance per square meter at a module temperature of $25^{\circ} \mathrm{C}$ [1]. Although this is a simple measure, it contains some subtleties.

- First, it subsumes energy conversion efficiency in the multijunction cell and in the concentrating optics in the sense that it focuses on the watts of DC power that result from those efficiencies. It also subsumes cost-effective efficiencies in manufacturing processes and in deployment methods. Because a system producer improves these efficiencies [2], those improvements (and the associated costs) are automatically reflected in a new figure for $\$ / \mathrm{W}$ and therefore do not need to be taken into account separately.

- Second, although $\$ / \mathrm{W}$ is a good measure for comparing among different HCPV systems, it is less useful for comparing HCPV with other electricity-generating technologies. Our estimate of the average capital cost of HCPV in 2014 is $\$ 2.40 / \mathrm{W}$ [3], and the world median capital cost of nuclear power is $\$ 4.10 / \mathrm{W}$ [4]. However, a nuclear power plant operates at near full capacity $24 \mathrm{~h} /$ day, whereas each peak watt of HCPV can generate far less electrical energy because it only produces during sunny conditions. Moreover, $\$ / \mathrm{W}$ refers only to the capital cost and does not include operating costs (e.g., fuel), which are very different among the various electricity generating technologies.

From the viewpoint of a solar farm operator, it is important to note that the $\$ / \mathrm{W}$ metric does not provide information about the amount of electrical energy, in kilowatt-hours, that the system can be expected to produce because that will depend 
on where geographically the system is installed due to factors such as solar resource, temperature, shading, and soiling. A solar farm operator needs to deploy the HCPV system at a location that produces enough $\mathrm{kWh}$ of electrical energy that can be sold for a sufficient price in $\$ / \mathrm{kWh}$ to cover the capital cost of the system in \$/W. There are two metrics that can be used for such an assessment:

- The levelized cost of electricity (LCOE) is a measure of the average cost of producing electricity over the lifetime of the system, and it can be used to compare among alternative power-generation technologies. It also enables the comparison between the effective cost of production and current electricity market rates: If the market rates are constant, this is an easy comparison.

- There are many situations when the value of electricity varies with the hour, month, and year, typically increasing at times of high demand. In these cases, an appropriate metric is the net present value (NPV) of the HCPV system, which takes into account the capital and operating costs together with the time-dependent value of the power generated.

Section 2 of this chapter covers the \$/W metric for HCPV systems including analysis of future trends; Sect. 3 provides a discussion of LCOE; and Sect. 4 presents the NPV metric for the operation of HCPV systems under different tariff structures.

\section{Capital Costs with Future Projections}

\subsection{Historic Capital Costs}

HCPV systems have been deployed commercially since 2007 at capital costs varying from $\$ 2.09$ to $\$ 10.00 / \mathrm{W}$ [3]. Costs have in general declined since 2007, but there has also been considerable variability in the price at which deals were negotiated within a single year (see Fig. 1).

To make a decision to invest in an HCPV system, a solar farm operator needs to consider not just the economics of investing today but also the economics of waiting to invest at a future point in time. The decline in HCPV system prices can be expected to continue into the future, which, coupled with increasing electricity prices in the future, may imply that it is more profitable to defer the investment decision until a future date. This option is explored in detail in Sects. 4.2 and 4.3 of this chapter. Hence, in addition to current system prices, the operator needs to have estimates of future prices.

A projection of capital costs to 2020 based on a log/linear regression analysis is given in Fig. 1, which shows $90 \%$ confidence intervals (CIs) on the projections to illustrate the extent of the price variability. Such a projection is based entirely on historical trends over time continuing into the future. It does not take into account other factors, such as why prices have declined in the past or whether price trends early in the deployment of a new technology, such as HCPV, might be different from trends after the technology is more established. 


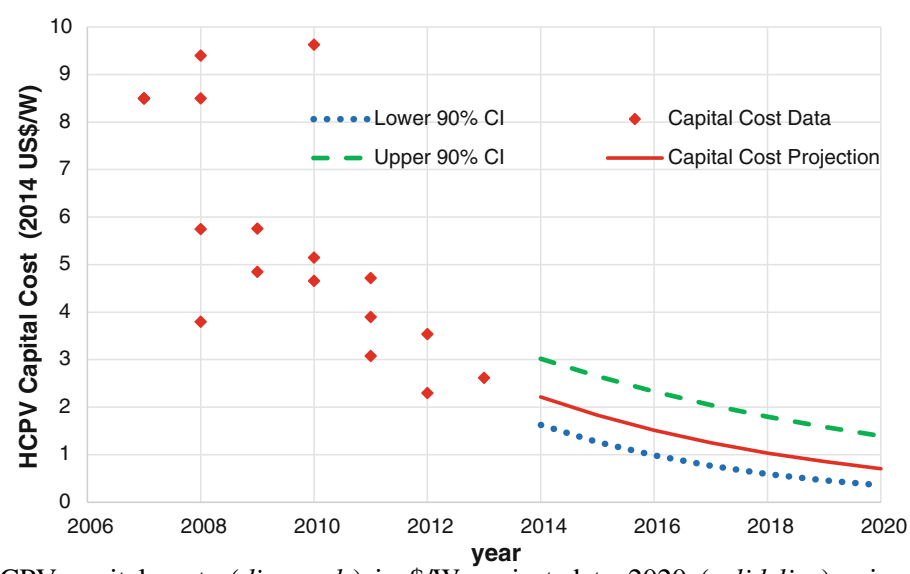

Fig. 1 HCPV capital costs (diamonds) in \$/W projected to 2020 (solid line) using log linear regression with $90 \%$ CIs. The dashes represent the upper CI, whereas the dots represent the lower CI. $\log ($ capital cost $)=-0.190($ year -2000$)+3.46$

\subsection{Learning Analysis}

An improved methodology for projecting technology prices is to relate prices not to time but to deployment volume. This approach has been used in a number of industries including solar power [5] and is based on the "experience curve" or "learning curve." The rationale behind this approach is that as HCPV is deployed, the industry gains experience and hence is able to operate more efficiently. Larger deployment volumes bring more revenue, and thus more research and development money is available to fund efficiency improvements in system technologies. In addition, increased deployments result in improvements in manufacturing and installation methods as well as efficiencies in scale, which further decrease costs. The learning curve equation is:

$$
C=\alpha V^{\beta}
$$

where $C$ is the cost of HCPV in $\$ / \mathrm{W}$, and $V$ is the cumulative deployment volume to date in megawatts (MW).

When deployment volume doubles, cost will change in the ratio $2^{\beta}$, thus resulting in a price reduction because typically $\beta$ is negative. The "learning rate" is defined as the proportional reduction in price and is given by:

$$
\mathrm{LR}=1-2^{\beta}
$$

In [3], we give HCPV deployment volumes for the period 2007-2013. They are likely more robust than the costs because industry players are more willing to disclose the size of a project in MW than the cost in $\$ / \mathrm{W}$. A $\log / \log$ regression of the data according to Eq. (1) results in an estimate of the learning rate of HCPV to 
be $18 \%$ with a $90 \% \mathrm{CI}$ of 14-22\% [3]. This is a rapid learning rate compared with $11 \%$ for concentrated solar power (CSP) systems [6] and $14 \%$ for PV systems [7]. A higher learning rate for HCPV technology puts the technology in a good competitive position relative to other solar technologies for two reasons. First, doubling in deployment volume can be expected to result in an $18 \%$ reduction in HCPV system price compared with lower percentages for CSP and PV. Second, because current cumulative deployment of HCPV (217.5 MW at the end of 2013) is <1\% of the solar global total, doubling can be achieved with a relatively small number of new MW-sized solar farms compared with the much higher volume required to double the cumulative deployment of CSP and PV.

We next show how the learning curve developed for HCPV can be used to derive more robust price projections than those shown in Fig. 1.

\subsection{Projections in Future Capital Costs}

The learning curve of Eq. (1) can be used to forecast future costs, $C$, as long as we know future deployment volume, $V$. Commercial market projections of deployment volume were obtained from Yole [8] and IHS [9] covering the period 2014-2020.

Three price projections were obtained based on three volume projections: Yole conservative, Yole optimistic, and IHS [3]. Each price projection has a $90 \% \mathrm{CI}$ resulting in 9 graphs. As a simplified summary of the many curves, Fig. 2 shows the three projections with only their outermost CIs shown.

These three forecasts give 2020 projections of $\$ 1.32, \$ 1.13$, and $\$ 1.17 / \mathrm{W}$, respectively, based on cumulative deployment volumes of 3.02, 5.12, and 4.65 GW. Comparing Figs. 1 and 2, it can be seen that the trend extrapolation in Fig. 1 results in a price of $\$ 0.71 / \mathrm{W}$ in 2020 , which is significantly lower than those in Fig. 2. The learning curve shows that to achieve a price of $\$ 0.71 / \mathrm{W}$ in 2020 , the cumulative deployment would need to be $26.5 \mathrm{GW}$, which is excessive compared with the projected volumes from Yole and IHS. In subsequent sections of this chapter, we therefore focus on a price projection derived from the Fig. 2 curves.

\section{LCOE with Future Projections}

The LCOE is a gauge of the costliness of an energy-generating technology over its operational lifetime. The LCOE for any electricity-generating system can be thought of as the break-even price today for selling electricity produced over all future years of operation $[10,11]$. The LCOE is particularly useful for comparing energy producing technologies that sell electricity to the energy marketplace at a consistent price over their operational lifetimes. 


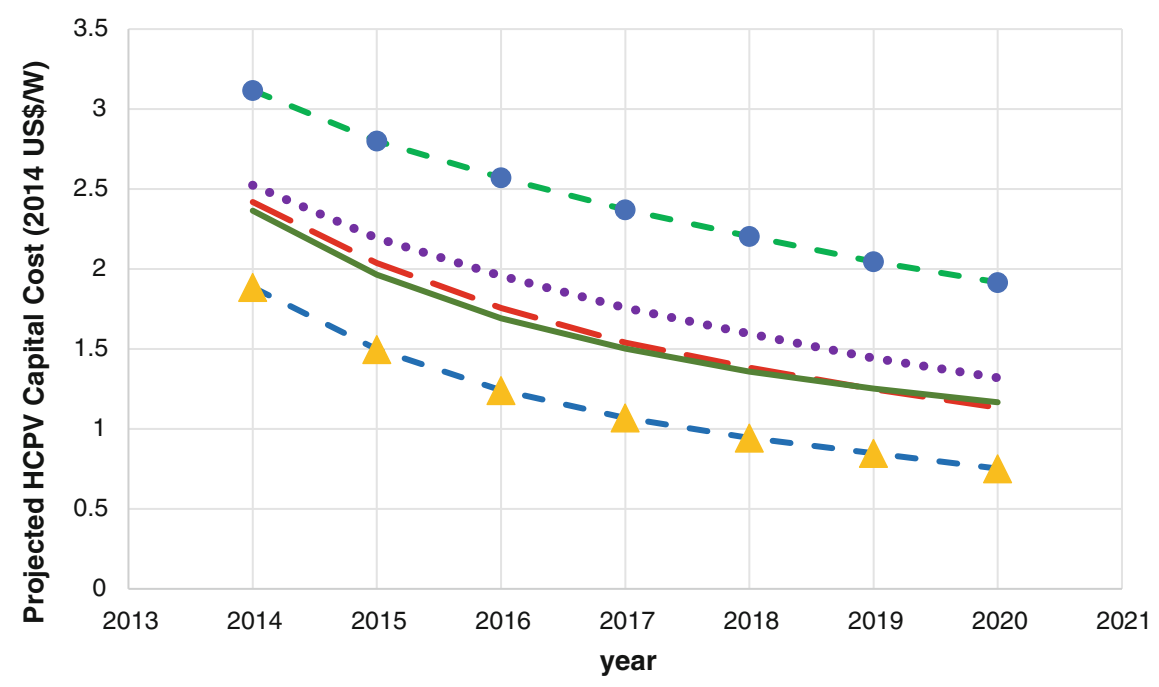

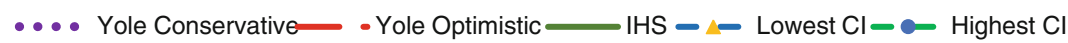

Fig. 2 Projections of HCPV costs in $\$ / \mathrm{W}$ based on the learning curve shown in Eq. (1) and projections of deployment volume from the Yole conservative [8] (dots conservative; long dashes optimistic) and IHS [9] (solid line). The outermost of the $90 \%$ CIs for all three projections are also shown, whereas lowest CI (dashes with triangles) is derived from the IHS and highest CI (dashes with circles) is derived the from Yole conservative

We can calculate the LCOE for a solar installation using:

$$
\text { Levelized Cost of Electricity }=\frac{I+\sum_{t=1}^{T} M_{t} \div(1+r)^{t}}{\sum_{t=1}^{T} E_{0}(1-d t) \div(1+r)^{t}}
$$

where $I$ is the initial capital expenditure, which occurs in year zero; $M_{t}$ is the operation and maintenance cost at time $t$; and $E_{0}$ is the amount of energy produced by the system in its first year. The HCPV module degradation rate is denoted by $d$; $r$ represents the risk-adjusted discount rate; and the total number of operating years is $T$.

The discount rate is regarded as a rate of required return on invested capital. It can be interpreted as the rate of return an investor could obtain from an alternate investment with a similar amount of risk [12]. Alternatively, the discount rate can be thought of as the cost of financing the debt owed to investors by an organization. For our analysis, we assume a discount rate of $7 \%$ based on [13, 25-27].

Operation and maintenance costs are incurred annually and depend on the $\mathrm{kW}$ size of the PV system. We assume these expenditures to be $\$ 33.25 / \mathrm{kW} /$ year for HCPV, which is 1.75 times the average cost for PV systems [20] due largely to tracking-equipment maintenance. Two additional one-time operational and maintenance expenses for inverter replacement and module recycling are included as fixed costs in our analysis in years 13 and 25 , respectively. The cost to replace the inverter 
is proportional to the $\mathrm{kW}$ size of the HCPV system, whereas the recycling expenditure is dependent on the physical size of the HCPV installation measured in square meters $\left(\mathrm{m}^{2}\right)$. The price to replace the inverter in year 13 of the analysis is presumed to be $\$ 0.16 / \mathrm{W}$, and this figure rests on an average 2012 commercial PV system inverter replacement charge of $\$ 0.19 / \mathrm{W}$ [13]. The expense to dismantle and recycle HCPV modules at the end of their operational lifetime is taken to be $\$ 18.25 / \mathrm{m}^{2}$ based on an up-to-date PV module dismantling and recycling fee [14] converted to American dollars at the 2014 average euro/dollar exchange rate at the time of writing.

Degradation is the gradual decrease over time in the energy output capability of solar modules resulting from their ongoing exposure to the outdoor elements [15]. Although an installation's degradation rate could vary over its operational lifetime [16], our HCPV analysis assumes a small, linear rate of $0.5 \%$ based on PV studies $[23,24]$. Given that HCPV degradation rates are currently unknown, and a recent publication indicated no measureable degradation after seven years [17], our analysis will assume that the HCPV degradation rate is the same as an accepted rate for PV technologies.

It is important to disclose the assumed input values for each variable found in Eq. (3), and these assumptions are given in Table 1. We presume that system prices are based on projections from Sect. 2.3, and for clarity, the yearly values are tabulated in Table 2 . The amount of energy produced by the system, $E_{0}$, has been calculated using direct normal irradiance (DNI) data for Las Vegas, Nevada, from the National Solar Radiation Data Base [18] and the Measurements and Instrumentation Data Center [19]. The former is a "typical meteorological year" DNI data set crafted from historic measured values in Las Vegas spanning 1979-2001. The latter data set, in contrast, contains consecutive hourly DNI data for Las Vegas spanning the period 2006-2013. The average of the two datasets provides a yearly DNI value of $2406 \mathrm{kWh} / \mathrm{m}^{2} /$ year. The first year's HCPV energy production is calculated by multiplying the amount of DNI by an assumed HCPV module efficiency and balance-of-system efficiency as follows:

$$
E_{0}=\mathrm{DNI} \times A \times \eta_{\mathrm{CPV}} \times \eta_{\mathrm{SYS}}
$$

where DNI is the annual DNI, $\eta_{\mathrm{CPV}}$ represents HCPV module efficiency, and $\eta_{\mathrm{SYS}}$ denotes HCPV system efficiency. The area, $A$, is the module area in $\mathrm{m}^{2}$ derived from the system size:

$$
A=\frac{P}{\eta_{\mathrm{CPV}} \times \mathrm{CSTC}}
$$

where $P$ is the rated DC power of the HCPV modules in watts, and CSTC is the DNI used for HCPV standard test conditions [1].

Inputting the "middle" 2014 input capital cost of $\$ 2.44 / \mathrm{W}$ together with the values of Table 1 into Eq. (3), the LCOE is found to be $\$ 0.125 / \mathrm{kWh}$. Thus, our solar installation would need to sell the electricity it produces at a price of $\$ 0.125 / \mathrm{kWh}$ over its 25 -year life span of operation to break even. 
Table 1 Input values for LCOE calculation using a 100-kW solar installation

\begin{tabular}{|c|c|c|c|c|}
\hline Parameter & Symbol & Value & Reference & Notes \\
\hline $\begin{array}{l}\text { HCPV-module } \\
\text { power rating }\end{array}$ & $P$ & $100 \mathrm{~kW}$ & & \\
\hline $\begin{array}{l}\text { Input capital } \\
\text { costs }\end{array}$ & $I$ & $\begin{array}{l}\$ 312,000 \\
\$ 244,000 \\
\$ 189,000\end{array}$ & & $\begin{array}{l}2014 \text { values from Eq. (1) } \\
\text { and Table } 2 \text { costs } C, \\
\text { using } I=C P\end{array}$ \\
\hline $\begin{array}{l}\text { Operation and } \\
\text { maintenance } \\
\text { costs }\end{array}$ & $M_{t}$ & $\$ 33.25 / \mathrm{kW}$ & {$[20]$} & $\begin{array}{l}1.75 \times \text { PV operation and } \\
\text { maintenance costs }\end{array}$ \\
\hline $\begin{array}{l}\text { DNI solar } \\
\text { resource }\end{array}$ & DNI & $\begin{array}{l}2406 \mathrm{kWh} / \mathrm{m}^{2} / \\
\text { year }\end{array}$ & {$[18,19]$} & For Las Vegas \\
\hline $\begin{array}{l}\text { HCPV module } \\
\text { efficiency }\end{array}$ & $\eta_{\mathrm{CPV}}$ & $30 \%$ & {$[21,22]$} & \\
\hline $\begin{array}{l}\text { HCPV system } \\
\text { efficiency }\end{array}$ & $\eta_{\mathrm{SYS}}$ & $80 \%$ & & \\
\hline $\begin{array}{l}\text { Concentrating } \\
\text { standard test } \\
\text { condition }\end{array}$ & CSTC & $1000 \mathrm{~W} / \mathrm{m}^{2}$ & {$[1]$} & \\
\hline $\begin{array}{l}\text { HCPV module } \\
\text { area }\end{array}$ & $A$ & $333 \mathrm{~m}^{2}$ & & By way of Eq. (5) \\
\hline $\begin{array}{l}\text { HCPV energy } \\
\text { production }\end{array}$ & $E_{0}$ & $192,493 \mathrm{kWh} /$ year & & By way of Eq. (4) \\
\hline $\begin{array}{l}\mathrm{HCPV} \\
\text { degradation } \\
\text { rate }\end{array}$ & $d$ & $0.5 \%$ & {$[23,24]$} & \\
\hline Discount rate & $r$ & $7 \%$ & \begin{tabular}{|l}
$13,25-$ \\
$27]$
\end{tabular} & \\
\hline $\begin{array}{l}\text { Project life } \\
\text { span }\end{array}$ & $T$ & 25 year & & \\
\hline
\end{tabular}

Table 2 HCPV capital cost scenarios (in $\$ / W$ ) used in our analysis

\begin{tabular}{l|l|l|l}
\hline Year & Upper $(\$ / \mathrm{W})$ & Middle $(\$ / \mathrm{W})$ & Lower $(\$ / \mathrm{W})$ \\
\hline 2014 & 3.12 & 2.44 & 1.89 \\
\hline 2015 & 2.80 & 2.06 & 1.50 \\
\hline 2016 & 2.57 & 1.80 & 1.24 \\
\hline 2017 & 2.37 & 1.60 & 1.07 \\
\hline 2018 & 2.20 & 1.45 & 0.94 \\
\hline 2019 & 2.05 & 1.31 & 0.85 \\
\hline 2020 & 1.92 & 1.21 & 0.75 \\
\hline
\end{tabular}

Looking toward future trends, we can incorporate the predicted declining capital costs from Table 2 to determine future LCOE values. Here we use the system prices from each of the "upper," "middle," and "lower" cost scenarios for each year, which modify $I$ from Eq. (3). At the same time, we maintain all other assumed values from Table 1. The result is a clearly declining LCOE with time as illustrated by Fig. 3. 
Fig. 3 The LCOE decreases over time due to decreasing HCPV system costs

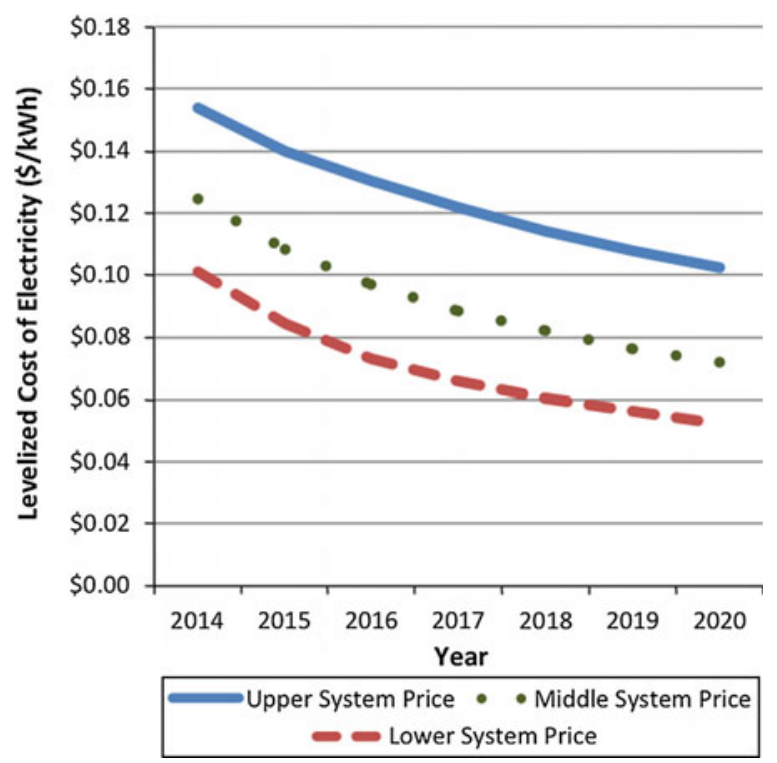

Thus, diminishing capital costs have a significant impact on the LCOE. The "middle" curve, for example, exhibits an LCOE of $\$ 0.072 / \mathrm{kWh}$ in 2020 , a decrease of $42 \%$ compared with 2014.

From Fig. 2, the "upper" prices correspond to system prices from the "highest CI," whereas the "lower" prices correspond to capital costs projections from the "lowest CI." The "middle" prices are a yearly average of Yole conservative, Yole optimistic, and IHS estimates also from Fig. 2.

The amount of DNI received by a solar installation also affects the LCOE. Las Vegas has a moderately strong solar resource compared with other geographic locations. Regions such as Northern Chile, Southern Africa, and Central China may achieve values in the range of $2600-3000 \mathrm{kWh} / \mathrm{m}^{2} /$ year, whereas the Northeastern United States, Southern Canada, and Central Europe have lower DNI resources in the range of $1300-1600 \mathrm{kWh} / \mathrm{m}^{2} /$ year. To study the sensitivity, we maintain all assumptions from Table 1 with the exception of $E_{0}$, which is modified to represent DNI levels spanning $1300-3000 \mathrm{kWh} / \mathrm{m}^{2} /$ year. As illustrated by Fig. 4, the LCOE decreases as the HCPV installation receives more DNI. Even a small increase in DNI by $100 \mathrm{kWh} / \mathrm{m}^{2} /$ year has a noticeable impact on the LCOE.

\subsection{LCOE Discussion}

The LCOE incorporates many different variables to determine the price at which electricity must be sold over the operational lifetime of the technology to break even. Combining its calculation with the projected future capital cost trends 
Fig. 4 The sensitivity of the LCOE to the solar resource, shown here for 2014; all curves will shift downwards in future years.

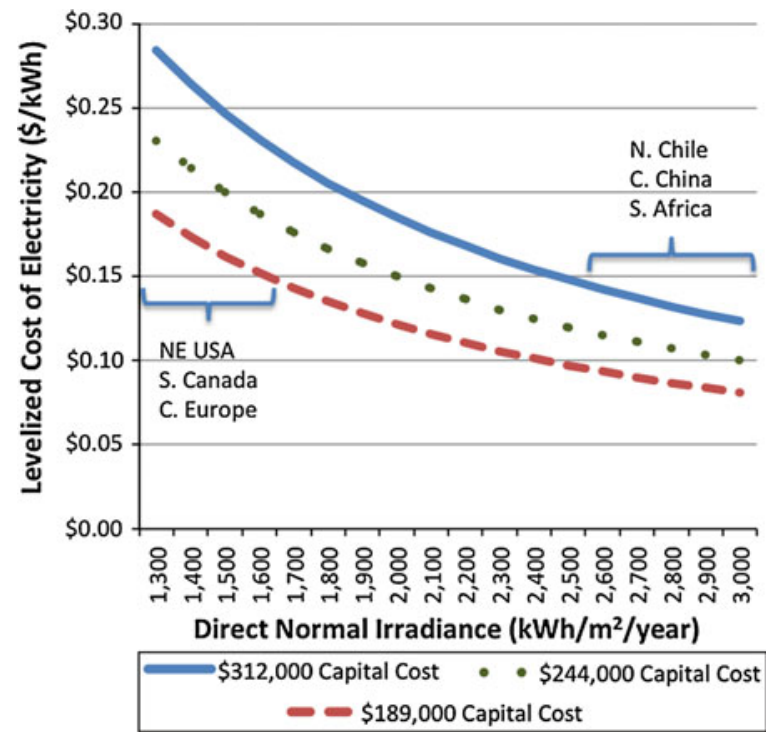

provides a useful indication of the future financial viability of HCPV projects. LCOE values will decrease as HCPV system prices decrease and may be less than the price of grid-produced electricity in some locations presently; this will spread to more locations as prices continue to decrease. The amount of DNI received by an HCPV installation has a significant impact on the LCOE; thus, locations with high DNI will achieve lower LCOE values before locations with low DNI resources. But this will be a dynamic situation: In future years, all prices will decrease. For example, again using the "middle" capital cost curve, Fig. 4 shows that a location with a low DNI of $1400 / \mathrm{kWh} / \mathrm{m}^{2} /$ year will have an LCOE of $\$ 0.214 / \mathrm{kWh}$ in 2014. However, this will decrease $42 \%$ by 2020 (applying the same trends as in Fig. 3) resulting in a value of $\$ 0.124 / \mathrm{kWh}$, which again may be competitive with 2020 electricity market prices.

The LCOE has limitations and is not an accurate indicator of an HCPV project's financial viability if the project sells its electricity at variable energy market prices. In addition, LCOE calculation is incapable of accounting for the value of electricity produced at different times of the day by intermittent energy-producing technologies such as HCPV. Both of these shortcomings, along with disagreements over the values of the inputs used in LCOE calculations, have led some to criticize the application of the LCOE to solar electricity generation [13, 23, 28]. Given these drawbacks, we will now explore an alternative method of assessing the economic viability of a solar installation. This method, often referred to as a "net present value" (NPV) analysis, enables us to take into account the varying wholesale electricity market prices and the time-dependent solar electricity production. As a result, we can obtain a clearer picture of the economic attractiveness of solar energy. 


\section{NPV with Future Projections}

\subsection{Methodology}

The NPV calculation incorporates several factors into one computation to gauge financial viability, which is measured by the present value of a series of future revenues and expenditures. A typical NPV calculation includes such items as the initial outlay of capital, yearly cash flows, and a discount rate. The yearly cash flows of a HCPV project incorporate the following items:

- Expenses: This includes operation and maintenance costs, an inverter replacement charge, and a recycling fee to be paid at the end of the project's life.

- Revenues: This includes value of the electricity produced by an HCPV installation over each year of operation subject to degradation of equipment over time and variable electricity rates.

To assess financial attractiveness, the sum of the HCPV installation's discounted revenue and expenses is compared with the initial outlay of capital. If the sum of the discounted revenue is greater than the initial outlay of capital, the project is said to have a positive NPV and is economically appealing. The NPV is calculated as:

$$
\text { Net Present Value }=-I+\sum_{t=1}^{T} \frac{R_{t}-M_{t}}{(1+r)^{t}}
$$

where $I$ is equal to the capital cost incurred in year zero; $T$ denotes the number of years the HCPV installation is operational; and $r$ signifies the discount rate. For each year $t$ of operation, $R_{t}$ is the revenue attributed to solar electricity production, and $M_{t}$ represents operation and maintenance costs. Assumptions and values for $I$, $T, M_{t}$, and $r$ are taken to be the same as indicated in Sect. 3 for the LCOE calculations. $R_{t}$ is new and requires further explanation.

At the beginning of year 1, the HCPV installation is assumed to be fully operational. The HCPV modules generate electricity and revenues during this first year of operation as well as in each subsequent year. Revenues, $R_{t}$, are equal to the amount of electricity produced, which is measured in $\mathrm{kWh}$, multiplied by an hourly electricity price as follows:

$$
R_{t}=\sum_{\mathrm{mh}} E_{\mathrm{mh}}(t) \times p_{\mathrm{mh}}(t)
$$

where $E_{\mathrm{mh}}(t)$ is the alternating current (AC) energy yield from the HCPV system, and $p_{\mathrm{mh}}(t)$ is the electricity price. Both of these variables depend on the month (m) and hour (h), which is the main differentiation from LCOE calculations that derive a fixed value for electricity costs. We assume that the values can be approximated as constant within a given hour of a given month and hence use the subscripts $m$ and $h$ for month and hour, respectively. For example, for 15:00-16:00 
in July, an energy yield and electricity price is determined by taking an average of all of the date from 15:00 to 16:00 in the month of July.

The annual energy yield of the HCPV modules begin with an energy yield of $E_{\mathrm{mh}}(0)$ and experience yearly linear degradation, $d$, as per:

$$
E_{\mathrm{mh}}(t)=E_{\mathrm{mh}}(0) \times(1-d \times t)
$$

in the same manner as for the LCOE calculation. As well, the $(t)$ dependence of the variable $p_{\mathrm{mh}}(t)$ is due to the fact that electricity rates may change year by year as will be examined in the case studies to follow.

Furthermore, the derivation of the AC energy yield follows similar lines as Eq. (4) from Sect. 3, but it now also maintains the month hour variability of the raw hourly DNI data:

$$
E_{\mathrm{mh}}(0)=\mathrm{DNI}_{\mathrm{mh}} \times A \times \eta_{\mathrm{CPV}} \times \eta_{\mathrm{SYS}}
$$

with $A, \eta_{\mathrm{CPV}}$, and $\eta_{\mathrm{SYS}}$ as defined in Table 1 .

Clearly, $\mathrm{DNI}_{\mathrm{mh}}$ and $p_{\mathrm{mh}}(t)$ will be dependent on the project's location, so complete calculations will be undertaken as two case studies in the upcoming sections. We will again use Las Vegas as an example, but we will also include an example calculation for Ottawa, Ontario, Canada. Las Vegas, with similar DNI levels as much of Western and Central Australia, Western South Africa, and Northwestern Saudi Arabia [29], is a more typical HCPV host site than Ottawa, at latitude $45^{\circ}$. For reference, Ottawa has similar DNI levels as Northern Italy and Southern Japan [29]. In our case study, we will show the economic viability of HCPV in Ottawa under the electricity-cost structure of a large business customer with peak demand $>3 \mathrm{MW}$.

We will consider the NPV for a project commencing in year 2014 as well as for investments deferred until future years. Unlike the LCOE analysis, which maintained a fixed system size of $100 \mathrm{~kW}$, the NPV analysis will instead maintain a fixed starting investment value of $\$ 1000$ in the year 2014. As a result, the deployed system size will vary with each calculation based on the $\$ / \mathrm{W}$ capital cost and project start date. As was the case for the LCOE analysis, the calculations are performed for each of the "lower," "middle," and "upper" system price projections, which are shown in Table 2.

Finally, we note that our NPV analyses will calculate electricity bill cost savings instead of revenues. In contrast to selling the electricity produced by our HCPV modules, we will assume that all power is consumed on-site, which consequently avoids the use of an equal amount of electricity from the power grid. By foregoing grid-produced electricity and associated fees, cost savings are generated. This distinction is particularly relevant to the Ottawa case study, where demand charges are decreased by the HCPV generation. 


\subsection{Las Vegas Case Study}

We now provide a detailed NPV calculation for an HCPV project in Las Vegas using the above-mentioned assumptions plus location-specific data for electricity rates and DNI. The same DNI datasets of $[18,19]$ are employed again to calculate an average $\mathrm{DNI}_{\mathrm{mh}}$.

For electricity prices, we employ time-of-use tariffs currently in effect for small businesses in Las Vegas as shown in Table 3. One can observe that the peak electricity price, which is significantly higher than off-peak prices, occurs over the course of the summer months during the afternoon and early evening. This time frame happens to coincide with the times at which solar modules typically produce their greatest amount of electricity, meaning that our HCPV system will, in all likelihood, generate a disproportionate amount of cost savings when electricity prices are at their peak. The inherent ability of HCPV to match peak electricity prices with peak electricity output is a significant benefit of employing the technology for the purpose of offsetting.

Our analysis assumes that electricity prices will increase at a rate of $0.4 \%$ /year, which is the average rate at which commercial electricity prices in the United States are expected to increase between now and 2040 [31]. We also assume that the hourly structure of the electricity prices remains the same in all years of operation. Thus, the value generated by offsetting, which we denoted as $R_{t}$ in Fig. 7, can be calculated using the more specific formula:

$$
R_{t}=\sum_{\mathrm{mh}} E_{\mathrm{mh}}(t) \times p_{\mathrm{mh}}(0) \times(1.004)^{t}
$$

where the $p_{\mathrm{mh}}(0)$ is obtained from Table 3 .

Table 4 displays an example complete NPV analysis for an HCPV project commencing in 2014 assuming a capital cost of $\$ 1.89 / \mathrm{W}$ in year zero and using the assumptions and calculation methods stated previously in this chapter.

According to Table 4, raw cost savings somewhat increase each year due to the assumed slight increase in electricity prices. However, once solar module degradation, the discount rate, as well as costs for operation and maintenance, inverter replacement, and recycling are taken into account, we observe decreasing present values of our net cost savings during the 25-year operational time frame. The result is a negative NPV of $-\$ 188.87$ meaning that the HCPV system does not generate

Table 3 Current time-of-use electricity prices for small businesses in Las Vegas, Nevada [30]

\begin{tabular}{l|l|l}
\hline Period & Time & $\begin{array}{l}\text { Electricity price } \\
\text { (per } \mathrm{kWh})\end{array}$ \\
\hline June 1st-September 30th & $13: 00-19: 00$ & $\$ 0.30149$ \\
\hline June 1st-September 30th & $19: 01-12: 59$ & $\$ 0.06262$ \\
\hline October 1st-May 31st & $00: 00-23: 59$ & $\$ 0.05005$ \\
\hline
\end{tabular}




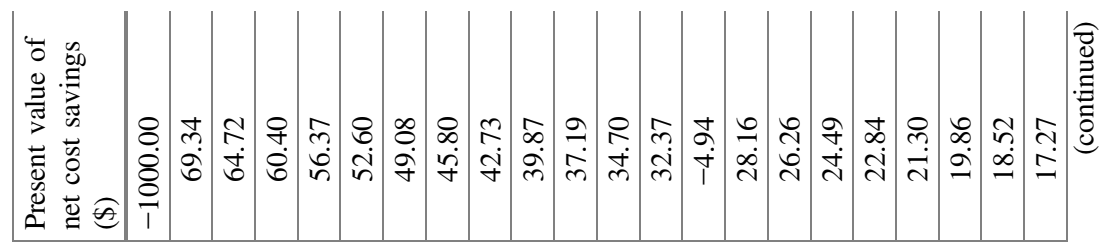

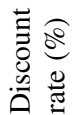

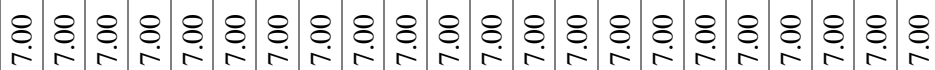

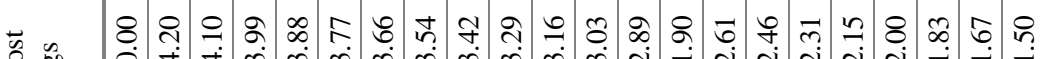
遂 芯空空

$\stackrel{丶}{\triangleright}$ 里

ธี

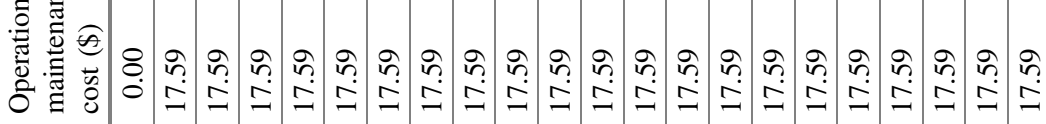

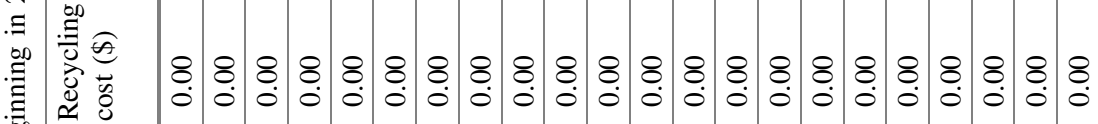
50

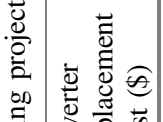

क्षे

टे

窟

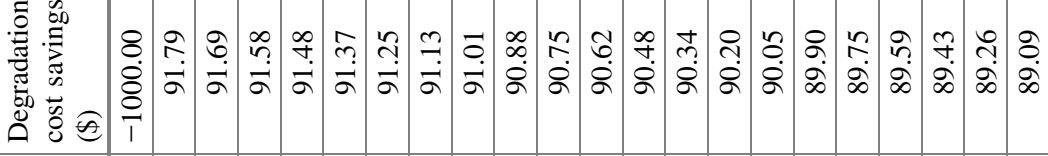

$\pi$

ప艹

茪

苞

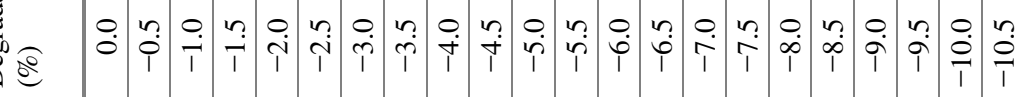

z

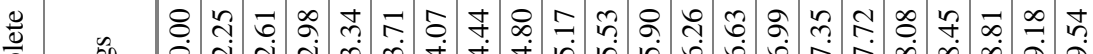

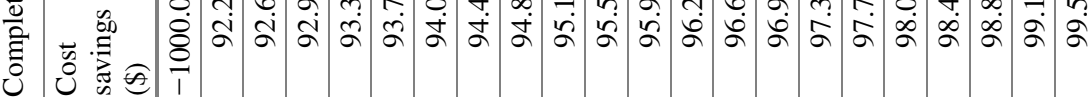

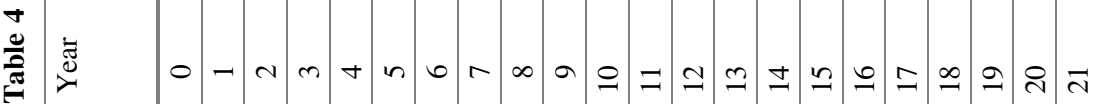




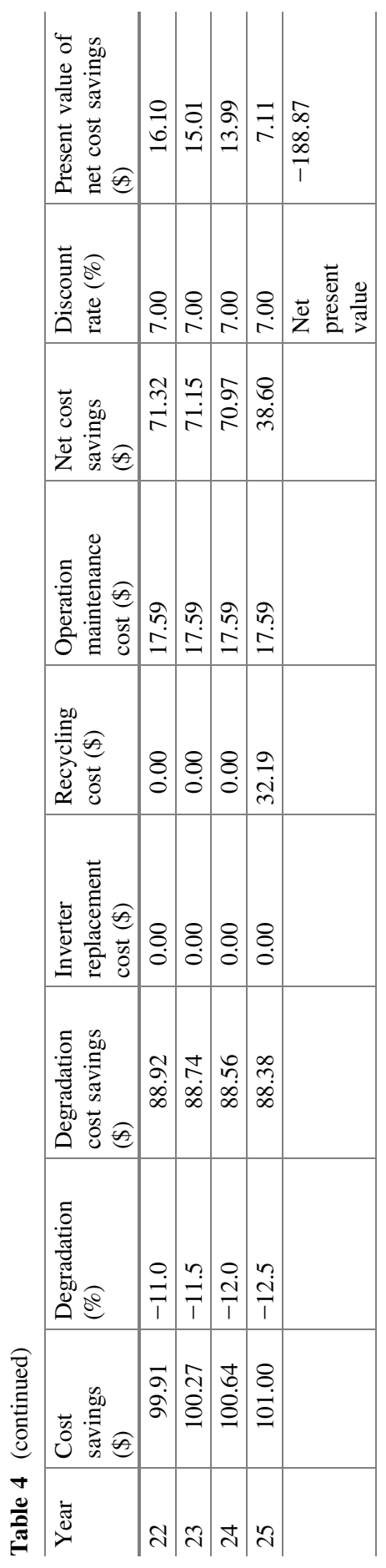


any net cost savings. Additional advantageous financial incentives - such as a tax rebate on solar equipment capital costs, renewable energy credits that supplement the price paid for clean energy, or even avoidance of paid sales taxes by the offsetwould improve the final financial result. However, these items are outside of the scope of our analysis.

Both of the 2014 "middle" and "upper" \$/W capital costs from Table 2 also yield negative NPV results. At installed costs of $\$ 2.44 / \mathrm{W}$ and $\$ 3.12 / \mathrm{W}$, our calculations produce NPVs of $-\$ 371.71$ and $-\$ 508.64$, respectively.

Without additional incentives, an HCPV system installed today in Las Vegas to offset grid-produced electricity charges for a small business will not generate a positive NPV over 25 years under any of the 3 pricing scenarios. However, given the steady decrease in HCPV capital costs between 2014 and 2020 as illustrated in [3] and shown in Table 2, we would be wise to investigate future NPVs from investing in an HCPV-offsetting project at a later time. By delaying investment, we can take advantage of a lower capital cost for the HCPV project as well as greater electricity rates to offset. Justification for deferral will be determined by comparing the NPV of projects with start dates between 2015 through to 2020 with each discounted back to 2014 .

The idea of forward-looking financial evaluation is a key component of our NPV analysis. When we defer investment, we assume that the $\$ 1000$ of investment capital is reinvested in risk-free United States treasury notes between 2014 and the start date of the project as per the rates in Table 5. This adds an additional incentive to defer investment because the interest collected, albeit small, increases the total amount of investment capital available.

For projects beginning in 2018 and 2020, we presume that interest on the $\$ 1000$ of investment capital is accrued for 4 years at $0.88 \%$ and for 6 years at $1.64 \%$, respectively.

In Fig. 5, we observe the negative NPVs in 2014 stated previously under each of the three pricing scenarios. However, looking no further than the following year, we can see a small, positive NPV for an HCPV system installed at the "lower" 2015 capital cost. Continuing further into the future, we can expect a positive NPV in 2018 according to the "middle" pricing scenario. The "upper" installation costs do not produce any positive NPVs for a HCPV-offsetting project in Las Vegas, Nevada, between 2014 and 2020.

Table 5 Average United States treasury yield rates for 1-, 2-, 3-, and 5-year treasury notes between January 1st and October 31st 2014 [32]

\begin{tabular}{l|l|l}
\hline Period (year) & Average 2014 rate $(\%)$ & Project start date \\
\hline 1 & 0.11 & 2015 \\
\hline 2 & 0.44 & 2016 \\
\hline 5 & 0.88 & 2017 \\
\hline
\end{tabular}




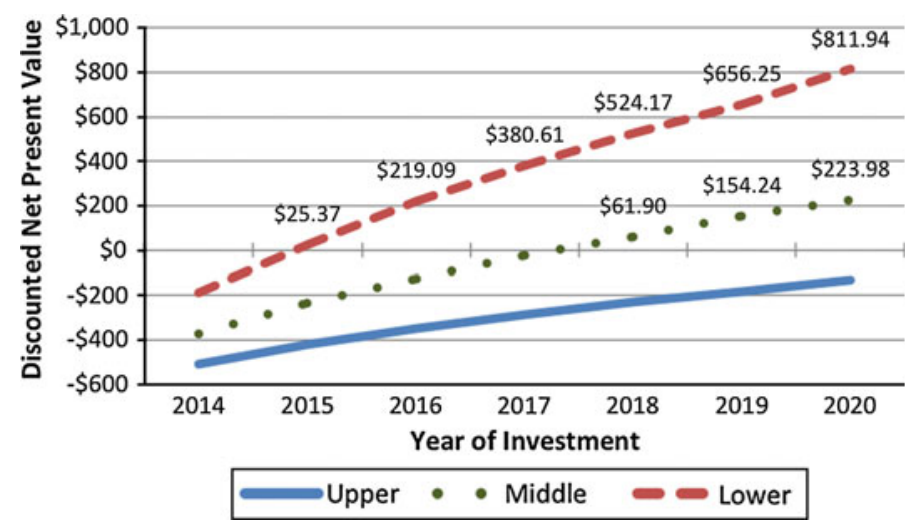

Fig. 5 Net present values calculated using the "upper," “middle," and "lower" capital cost scenarios for Las Vegas, Nevada. Each symbol represents a complete NPV analysis discounted back to 2014

In summary, we examined the prospect of using HCPV to offset electricity costs at a small business in Las Vegas, Nevada, according to current time-of-use rates. Per our results, HCPV investment in Las Vegas for offsetting will be profitable as soon as 2015 if installation prices are low. Otherwise, investment will not be profitable until 2018 or later depending on the capital cost scenario. We will now turn our attention to an $\mathrm{HCPV}$-offsetting project in Ottawa, Ontario, for comparison with these results.

\subsection{Ottawa Case Study}

One might expect an HCPV project to be unviable in Ottawa, Ontario, given the much lower DNI solar resource in this location compared with Las Vegas, Nevada. However, because of a significantly different electricity rate structure for Ontario customers, with peak energy demands in excess of $3 \mathrm{MW}$, the actual result is rather interesting. Our Ottawa analysis will employ the same assumptions about HCPV performance, capital, and operating costs from the previous sections but with different DNI data and additional electricity charges to offset for cost savings.

We obtained DNI data for Ottawa from the Canadian Weather Energy and Engineering Datasets [33]. The Ottawa data set contains hourly DNI readings between January 1, 1953, and December 31, 2005, and has an average yearly DNI total of $1455 \mathrm{kWh} / \mathrm{m}^{2} /$ year. From this data set, we developed average $\mathrm{DNI}_{\mathrm{mh}}$ data, which were used to derive $\mathrm{AC}$ energy yield values $E_{\mathrm{mh}}(0)$ and $E_{\mathrm{mh}}(t)$ in the exact same manner as Las Vegas. What is unique to this case study is that the calculation of cost savings, $R_{t}$, will require three subcalculations due to the manner in which 
customers consuming a large quantity of electricity are charged for electricity ${ }^{1}$ and how the value from offsetting each of these charges is calculated. The solar project works toward offsetting electricity bill charges by providing both $\mathrm{kWh}$ of energy and $\mathrm{kW}$ of power, which decrease demand charges using the following formula:

$$
R_{t}=\sum_{\mathrm{mh}} E_{\mathrm{mh}}(t) p_{1, \mathrm{mh}}(t)+12 p_{2}(t) \sum_{\mathrm{mh}} \gamma_{2, \mathrm{mh}} \frac{E_{\mathrm{mh}}(t-1)}{1 \mathrm{~h}}+p_{3}(t) \sum_{\mathrm{mh}} \gamma_{3, \mathrm{mh}} \frac{E_{\mathrm{mh}}(t)}{1 \mathrm{~h}}
$$

The centre term in (11) is not present for $t=1$ because the CPV system is being built in year zero and thus generates no power in that year. In addition, in Eq. (11) the $\gamma_{i}$ terms represent probabilities, and the $p_{i}$ terms represent the three different rate charges, as will be explained in the following paragraphs.

First, customers who consume a large amount of electricity in Ontario are charged the wholesale price of electricity for the energy they consume, which is measured in hourly increments. They also pay other fees that are charged per $\mathrm{kWh}$ of energy consumed, which for large customers in Ottawa averaged approximately $50 \%$ of wholesale costs in 2013. Thus, the price $p_{1}$ represents both of these charges and is computed herein as 1.5 times the Hourly Ontario Electricity Price data set for 2013. When we multiply $p_{1}$ by the HCPV energy yield $E_{\mathrm{mh}}$ corresponding to the same hour, we determine that particular hour's cost savings. An overall summation of all hours in the year is performed.

Second, there is a monthly charge based on a grid peak demand pricing structure. For each month, the charge is based on the customer's proportion of the Ontario grid's total electricity demand during the province's five greatest demand peaks from the previous calendar year [34] multiplied by the month's grid demand charge. Those grid peaks typically occur on hot, sunny afternoons in the summer due to air conditioning use. To calculate the average expected power generation that an HCPV project will have in those hours, we multiply the probability of the grid peak occurring during a particular hour $\gamma_{2 \text {,mh }}$ [34] by the average expected HCPV energy yield for the same hourly interval $E_{\mathrm{mh}}(t)$. This figure is then divided by $1 \mathrm{~h}$ to convert into power. A graph displaying the hours in which grid peak demands have occurred, and the associated probability of these occurrences is shown in Fig. 6. The overall sum of the hours provides the decrease in net grid peak demand that the customer can expect to have achieved in the previous year and which will become their factor for all charges in the subsequent year. Thus, the sum is then multiplied by the monthly grid peak demand charge $p_{2}$ of $\$ 24.35 / \mathrm{kW}$ (converted from $26.70 \mathrm{CAD} / \mathrm{kW}[34,35])$ and then by 12 to calculate the total peak demand cost savings for 1 year.

Third, the local distribution company charges a monthly delivery fee based on the $\mathrm{kW}$ consumed during the customer's consumption peak each month. For our analysis, we assume a simplified customer whose peak demand occurs between

\footnotetext{
${ }^{1}$ Canadian electricity prices and related charges are converted to American dollars.
} 


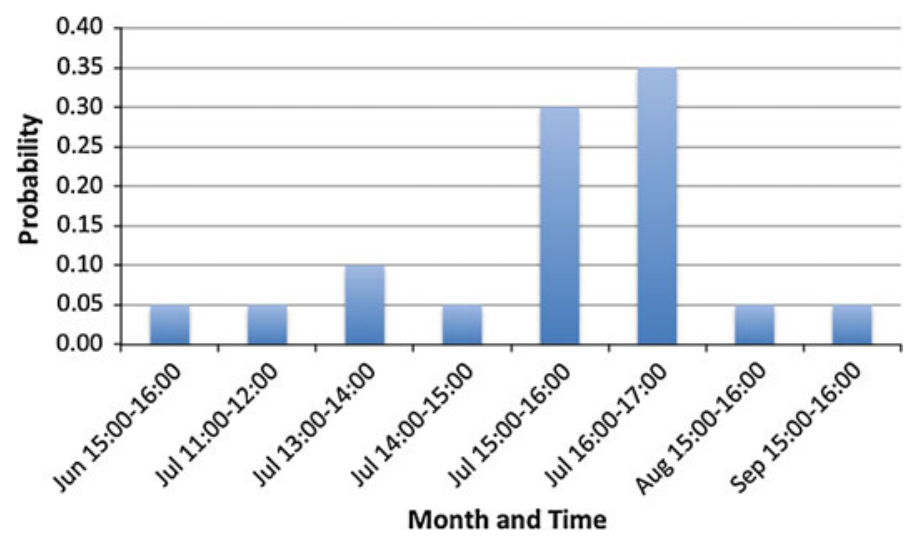

Fig. 6 Historical grid peak demand charge occurrences and associated probabilities. All individual hours for which the probability is nonzero during the 4 years of the program are provided

09:00 and 10:00 from November to March and between 13:00 and 14:00 from April to October. These times represent substantial air conditioner use in summer afternoons and morning peaks in the colder months of the year when the business commences daily operations. This is equivalent to setting the probability $\gamma_{3 \text {, mh }}$ to 1 for these $12 \mathrm{~h}$ of the year and to zero for all others hours. HCPV energy $E_{\mathrm{mh}}(t)$ is again divided by $1 \mathrm{~h}$ to convert into power. The sum is multiplied by the monthly delivery charge $p_{3}$ of $\$ 6.42 / \mathrm{kW}$ for large consumers of Hydro Ottawa (converted from $7.04 \mathrm{CAD} / \mathrm{kW}$ [36]) and then multiplied by 12 to calculate the total customer demand cost savings for 1 year.

A sum of these three terms provides us with the total cost savings for 1 year for offsetting electricity charges. The next step is to consider how the rates $p_{1, \mathrm{mh}}(t)$, $p_{2}(t)$, and $p_{3}(t)$ will change over time in years $t$ to estimate the quantity of cost savings our HCPV installation will generate during each of its 25 years of operations. We turn to the Government of Ontario's most recent Long-Term Energy Plan, which was released in 2013 [37]. It provides estimates for future changes to wholesale electricity prices and rates of peak demand charges, which we incorporate into the NPV calculation for future years [38]. For example, the Long-Term Energy Plan projects that wholesale electricity prices $p_{1, \mathrm{mh}}(t)$ are expected to nearly double between 2013 and 2023, while at the same time grid peak charges $p_{2}(t)$ are anticipated to slightly decrease. The large energy customer's monthly peak consumption charges, $p_{3}(t)$, are assumed to remain relatively stable over time [37].

Clearly, this is a complex calculation, and more detailed explanations can be found in [38]. The entire NPV calculation is once again analysed for HCPV projects commencing in 2014-2020 (inclusive) and discounted back to 2014 with results shown in Fig. 7.

According to Fig. 7, we will realize negative discounted NPVs if we make an HCPV investment in 2014 under any of the three pricing scenarios from Table 2. However, similar to the case of Las Vegas, deferring HCPV investment by just 


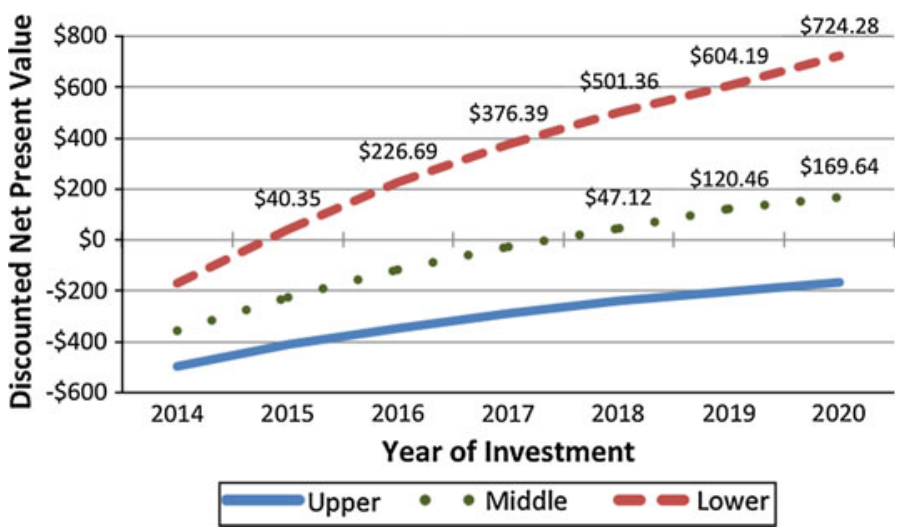

Fig. 7 Discounted NPVs for each of the "upper," "middle," and "lower" HCPV pricing scenarios for Ottawa, Ontario. The $\$ / \mathrm{W}$ capital costs used to calculate these values are shown in Table 2

1 year to 2015 yields a positive NPV under the "lower" pricing scenario even when the NPV is discounted back to 2014 at a discount rate of $7 \%$. By 2018, there is a positive NPV for the "middle" price projection, and profitability increases with each successive year. Regarding the "higher" installed capital costs, Fig. 7 shows an increase in NPV between 2014 and 2020, but these figures fail to cross into positive territory during this time frame.

\subsection{NPV Discussion}

Compared with Las Vegas, Ottawa is not a typical location for an HCPV installation. However, we illustrated in Sect. 4.3 that an HCPV-offsetting project for a large business in Ottawa can generate cost savings given the electricity pricing structure in place in Ontario. We observe multiple commonalities between the NPV results for Ottawa and Las Vegas. In 2014, HCPV offsetting projects in both locations did not generate any positive net cost savings. But we do observe positive cost savings in both Ottawa and Las Vegas beginning in 2015 under the "lower" pricing scenario and in 2018 according to the "middle" capital costs. Neither location realizes positive net cost savings under the "upper" pricing scenario.

In 2015, when positive net cost savings are realized under the "lower" pricing scenario in both locations, Ottawa's discounted NPV of $\$ 40.35$ is greater than the $\$ 25.37$ discounted NPV in Las Vegas. In 2016, Ottawa also has a higher discounted NPV of \$226.69 compared with Las Vegas' \$219.09. However, we see a changeover in 2017 when Las Vegas replaces Ottawa as the city with the greater discounted NPV from offsetting electricity charges. This is due to projections of diminishing grid peak rates in Ontario [37, 38]. Although DNI levels for Las Vegas are significantly greater than those for Ottawa, the electricity charge structure in 
Ontario keeps Ottawa's NPVs in line with those observed in Las Vegas. Under average projected prices, our Ottawa and Las Vegas analyses have shown that HCPV projects built in 2018 or thereafter are expected to be profitable when selling electricity at market rates without any subsidies or incentives.

\section{Conclusions}

HCPV technology has exhibited strong efficiency improvements and provides a compelling promise toward further significant efficiency gains. The marketplace for HCPV is considered nascent, meaning it has room for manufacturing cost-efficiencies as it further matures and expands. This chapter shows, conclusively, that HCPV technology also has a strong track record and promises decreasing system costs and financial viability in the future.

The three metrics for financial analysis assessed in this chapter were capital costs (in \$/W), LCOE (in \$/kWh), and NPV (in \$). First, capital costs for HCPV systems were shown to have decreased at a steady, significant rate. The trend is characterised by a learning rate of $18 \%$ with a $90 \%$ CI of $14-22 \%$. This is greater than those for other solar system technologies. Our analysis further combines this learning rate with future scenarios for HCPV-deployed volume growth rates from three different market scenarios to provide projections for future capital costs of HCPV systems. By 2020, prices are projected to reach $\$ 1.32, \$ 1.13$, and $\$ 1.17 / \mathrm{W}$ corresponding to cumulative deployment volumes of 3.02, 5.12, and $4.65 \mathrm{GW}$, respectively. It should be noted that these cumulative volumes are all extremely small compared with the size of the entire solar industry and thus allow for strong growth to quickly enable the further realization of very low cost HCPV. The research as a whole indicates that HCPV systems are already competitive with other forms of solar energy and are projected to show the strongest decreases in capital costs over time. Thus, now is a realistic time to begin considering HCPV technologies for future projects.

Using these capital cost projections, we evaluated the cost of electricity produced from HCPV using the LCOE method. This method is useful for generalized evaluations, in particular when electricity is sold at a flat rate, and for comparisons with other electricity-generating technologies. We undertook a case study for a HCPV deployment in Las Vegas, which has an average yearly DNI of $2406 \mathrm{kWh} / \mathrm{m}^{2}$. We calculated an LCOE of $\$ 0.125 / \mathrm{kWh}$ in 2014 under the "middle" capital cost scenario, which decreased to $\$ 0.072 / \mathrm{kWh}$ by 2020 . The analysis was further augmented to include "lower" and "upper" capital cost projections. Furthermore, the sensitivity of LCOE to the DNI resource was explored again for multiple capital cost projections. Clearly, the LCOE depends on both DNI and capital costs: For "middle" cost projections, the LCOE may be as low as $\$ 0.10 / \mathrm{kWh}$ in high-DNI regions today. These electricity prices are extremely competitive with market rates for electricity in most parts of the world, and these low prices will rapidly extend to lower DNI regions in future years. 
For project locations and situations where electricity rates vary according to different hours of the day, alternate approaches must be employed to assess financial viability. We have developed an NPV methodology with month hour computation of revenues. Two case studies were undertaken using this methodology: Las Vegas, Nevada (with time-of-use electricity prices) and Ottawa, Ontario (with a complex rate structure and dependencies on grid and customer peak demands). HCPV provides a good match for high electricity prices and peak demand hours, which typically occur around midday during the summer months. This matching improves HCPV system profitability much more so than if nonpeaking average electricity rates were in place. Both case studies showed negative, nonattractive NPVs for 2014. However, when considering future capital cost projection scenarios for the years 2014 and 2020, both studies exhibited profitability for 2015 (2018) under "lower" ("middle") capital cost scenarios. Any subsidies or incentives, if available, for HCPV projects would further aid with profitability at earlier dates.

Given that project development can often take $\geq 3$ years from initial concept to a fully realized system, our predictions indicate that interested institutions, installers, developers, and policymakers should already have HCPV technology on their radar as a profitable candidate for renewable energy generation.

\section{References}

1. IEC (2013) IEC 62670-1 Photovoltaic concentrators (CPV)-performance testing-part 1: standard conditions

2. National Renewable Energy Laboratory (2014) Best research cell efficiencies. http://www.nrel. gov/nCPV/images/efficiency_chart.jpg. Accessed 12 Sept 2014

3. Haysom JE, Jafarieh O, Anis H, Hinzer K, Wright D (2014) Learning curve analysis of concentrated photovoltaic systems. In: Prog Photovoltaics: Res Appl doi:10.1002/pip.2567

4. World Nuclear Association (2014) The economics of nuclear power. http://www.worldnuclear.org/info/Economic-Aspects/Economics-of-Nuclear-Power/. Accessed 15 Sept 2014

5. Luque A, Hegedus S (2011) Handbook of photovoltaic science and engineering, 2nd edn. Wiley, Chichester

6. Hernandez-Moro J, Martınez-Duart JM (2013) Analytical model for solar PV and CSP electricity costs: present LCOE values and their future evolution. Renew Sustain Energy Rev 20:119-132. doi:10.1016/j.rser.2012.11.082

7. Kersten F, Doll R, Kux A, Huljić DM, Görig MA, Breyer C, Müller JW, Wawer P (2011) PV learning curves: past and future drivers of cost reduction. In: Proceedings of the 26th European photovoltaic solar energy conference (EUPSEC), Hamburg, Germany, 5-9 Sept 2011

8. Yole Développement (2013) High-concentration photovoltaics business and technology update report. http://www.i-micronews.com/reports/High-Concentration-PhotovoltaicsBusiness-Update-report/5/358/. Accessed 13 Sept 2014

9. IHS (2013) Concentrated photovoltaic solar installations set to boom in the coming years. http://press.ihs.com/press-release/design-supply-chain/concentrated-photovoltaic-solarinstallations-set-boom-coming-year. Accessed 13 Sept 2014

10. Darling SB, You F, Veselka T, Velosa A (2011) Assumptions and the levelized cost of energy for photovoltaics. Energy Environ Sci 4:3133-3139. doi:10.1039/c0ee00698j 
11. Borenstein S (2012) The private and public economics of renewable electricity generation. J Econ Perspect 26(1):67-92. doi:10.1257/jep.26.1.67

12. Pratt SP, Grabowski RJ (eds) (2014) Defining cost of capital. In: Cost of capital: applications and examples. Wiley, Hoboken, pp 1-10

13. Bazilian M, Onyeji I, Liebreich M, MacGille I, Chased J, Shahf J, Gieleng D, Arenth D, Landfeari D, Zhengrongj S (2013) Re-considering the economics of photovoltaic power. Renew Energy 53:329-338. doi:10.1016/j.renene.2012.11.029

14. Di Francia G (2013) The impact of recycling policies on the photovoltaic levelized cost of the electricity. In: Proceedings of the international conference on renewable energy research and applications (ICRERA), Madrid, Spain, 20-23 Oct 2013

15. Lyden S, Haque ME, Gargoom A, Negnevitsky M, Muoka PI (2012) Modelling and parameter estimation of photovoltaic cell. In: Proceedings of the 22nd Australasian universities power engineering conference (AUPEC), Bali, Indonesia, 26-29 Sept 2012

16. Phinikarides A, Kindyni N, Makrides G, Georghiou GE (2014) Review of photovoltaic degradation rate methodologies. Renew Sustain Energy Rev 40:143-152. doi:10.1016/j.rser. 2014.07.155

17. Gerstmaier T, Rottger M, Zech T, Moretta R, Braun C, Gombert A (2014) Five years of CPV field data: results of a long-term outdoor performance study. Paper presented at the 10th international conference on concentrating photovoltaics, Albuquerque, New Mexico, 7-9 Apr 2014

18. National Renewable Energy Laboratory (2014) 723860 Las Vegas McCarran Intl AP. In: National solar radiation data base 1991-2005 update: typical meteorological year 3. http:// rredc.nrel.gov/solar/old_data/nsrdb/1991-2005/data/tmy3/723860TY.csv. Accessed 2 Oct 2014

19. Nevada Power (2014) DAILY PLOTS and RAW DATA FILES 27 Mar 2006-1 Oct 2014. http://www.nrel.gov/midc/apps/day.pl?NPC. Accessed 2 Oct 2014

20. National Renewable Energy Laboratory (2013) Distributed generation energy technology operations and maintenance costs. http://www.nrel.gov/analysis/tech_cost_om_dg.html. Accessed 2 Oct 2014

21. Fernández EF, Pérez-Higueras P, Garcia Loureiro AJ, Vidal PG (2013) Outdoor evaluation of concentrator photovoltaic systems modules from different manufacturers: first results and steps. Prog Photovoltaics Res Appl 21(4):693-701. doi:10.1002/pip.1262

22. Kurtz S (2012) Opportunities and challenges for development of a mature concentrating photovoltaic power industry. Available via National Renewable Energy Laboratory Publications. http://www.nrel.gov/docs/fy13osti/43208.pdf. Accessed 3 Oct 2014

23. Branker K, Pathak MJM, Pearce JM (2011) A review of solar photovoltaic levelized cost of electricity. Renew Sustain Energy Rev 15(9):4470-4482. doi:10.1016/j.rser.2011.07.104

24. Reichelstein S, Yorston M (2013) The prospects for cost competitive solar PV power. Energy Policy 55:117-127. doi:10.1016/j.enpol.2012.11.003

25. Swift KD (2013) A comparison of the cost and financial returns for solar photovoltaic systems installed by businesses in different locations across the United States. Renew Energy 57:137143. doi:10.1016/j.renene.2013.01.011

26. Barbose G, Darghouth N, Weaver S, Wiser R (2013) Tracking the sun VI: an historical summary of the installed price of photovoltaics in the United States from 1998 to 2012. Available via Lawrence Berkeley National Laboratory. http://emp.lbl.gov/sites/all/files/lbnl6350e.pdf. Accessed 6 Oct 2014

27. Poullikkas A, Hadjipaschalis I, Kourtis G (2013) Parametric assessment of concentrated photovoltaic parks for the Mediterranean region. Int J Sustain Energ 32(1):42-52. doi:10. 1080/14786451.2011.595794

28. Joskow PL (2011) Comparing the costs of intermittent and dispatchable electricity generating technologies. Am Econ Rev Pap Proc 100(3):238-241. doi:10.1257/aer.100.3.238

29. GeoModal Solar (2013) World map of direct normal irradiation. http://solargis.info/doc/_pics/ freemaps/1000px/dni/SolarGIS-Solar-map-DNI-World-map-en.png. Accessed 30 Oct 2014 
30. NV Energy (2014) Business time of use for southern service territory. https://www.nvenergy. com/business/paymentbilling/timeofuse.cfm. Accessed 7 Oct 2014

31. U.S. Energy Information Administration (2014) Annual energy outlook 2014. Available via U. S. Energy Information Administration Independent Statistics \& Analysis. http://www.eia.gov/ forecasts/aeo/pdf/tbla8.pdf. Accessed 8 Oct 2014

32. U.S. Department of the Treasury (2014) Daily treasury yield curve rates. http://www.treasury. gov/resource-center/data-chart-center/interest-rates/Pages/TextView.aspx?data=yieldYear\& year=2014. Accessed 31 Oct 2014

33. Government of Canada (2013) Index of /Pub/Engineering_Climate_Dataset/Canadian_ Weather_Energy_Engineering_Dataset_CWEEDS_2005/ZIPPED FILES/ENGLISH/. ftp:// client_climate@ftp.tor.ec.gc.ca/Pub/Engineering_Climate_Dataset/Canadian_Weather_Energy_ Engineering_Dataset_CWEEDS_2005/ZIPPED\%20FILES/ENGLISH/ONTARIO.zip. Accessed 6 Oct 2014

34. Independent Electricity Service Operator (2014) Global adjustment for class A. http://www. ieso.ca/Pages/Participate/Settlements/Global-Adjustment-for-Class-A.aspx. Accessed 7 Oct 2014

35. Independent Electricity Service Operator (2014) Global adjustment-archive. http://www. ieso.ca/Pages/Participate/Settlements/Global-Adjustment-Archive.aspx. Accessed 6 Oct 2014

36. Hydro Ottawa (2014) Rates and conditions. https://hydroottawa.com/business/rates-andconditions/. Accessed 6 Oct 2014

37. Ontario Power Authority (2014) Cost of electricity service 2013 LTEP: module 4. Available via Ontario Power Authority. http://powerauthority.on.ca/sites/default/files/planning/LTEP2013-Module-4-Cost.pdf. Accessed 7 Oct 2014

38. Tomosk S (2015). An application of photovoltaic offsetting to reduce electricity costs at Ontario data centers. Master's thesis, University of Ottawa (in writing) 